\title{
Okul Öncesi Fen Eğitiminde Açık Kaynak Kodlu Planetaryumların Kullanılabilirliği
}

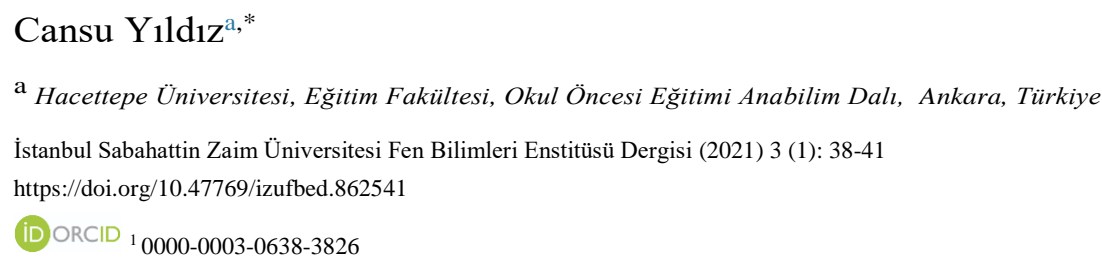

\begin{tabular}{l}
\hline YAYIN BİLGİSI \\
\hline Yayın geçmişi: \\
Gönderilen tarih: 16 Ocak 2021 \\
Kabul tarihi: 23 Şubat 2021 \\
\hline Anahtar kelimeler: \\
Açık kaynak kodlu yazılım \\
Planetaryum \\
Okul öncesi eğitim \\
Fen
\end{tabular}

\section{ÖZET}

Astronomi ve astronomik kavramlar insanoğlunun yüzyıllardır merak ettiği konular arasında yer almaktadır. Özellikle çocuklar, erken yaşlardan itibaren çevrelerini gözlemlemeye, Uzay, Dünya ve diğer gök cisimleri hakkında sorular sormaya başlarlar. Planetaryumlar, okul öncesi dönem çocukları için soyut olan bu kavramları somutlaştırmaya yarayan öğrenme ortamlarındandır. Bu çalışmada, açık kaynak kodlu planetaryum örneklerinden Stellarium ile Celestia incelenmiş ve okul öncesi fen eğitiminde kullanılabilirliği tartışılmıştır.

\section{Usability of open source planetarium softwares in preschool science education}

\begin{tabular}{l}
\hline ARTICLE INFO \\
\hline Article history: \\
Received: 16 January 2021 \\
Accepted: 23 February 2021 \\
\hline Key words: \\
Open source software \\
Planetarium \\
Preschool education \\
Science
\end{tabular}

\section{Giriş}

Astronomi kavramları, bireylerin Dünya'daki yaşam hakkındaki temel görüşlerini ve insanoğlunun varlığına ilişkin sorgulamalarını şekillendirir. Yüzyıllardan beri insanlığın merakını çeken astronomi, çocuklar için de bir merak konusu ve ilgi alanıdır (Sharp, 1999). Bilime ilişkin pek çok kavram gibi astronomi kavramları da okul öncesi dönemde oluşmaya başlamaktadır (Lind, 1999). Çocukların astronomiye ilişkin bilgileri, önceki öğrenmeleri, deneyimleri ve gökyüzü gözlemlerinin sonucunda zihinlerinde şekillenir (İzgi Onbaşılı ve Siper Kabadayı, 2019). Güneş, gezegenler ve yıldızlar çocuklar için etkileyici konulardır. Keşif ve öğrenme isteğinin yoğun olduğu okul öncesi dönemde çocuklar, gezegenlerin özelliklerini, hareketlerini ve fiziksel görünümlerini merak eder, gece-gündüz olayları ve gökyüzü ile ilgilenirler. Bu ilgi ve merak, çocukları günlük yaşamlarında gök cisimlerini ve gök olaylarını gözlemlemeye yöneltir (Kallery, 2011; Timur, Yalçınkaya-Önder, Timur ve Özeş, 2020). Çocukları erken yaşlarda astronomi ile tanıştırmaları bazı nedenlerden dolayı gereklidir. İlk olarak gündüz ve gece oluşumu, Ay ve Güneş tutulmaları, Ay'ın evreleri gibi astronomik olaylar ya da gök 
cisimlerinin şekillerinin ve diğer özelliklerinin anlaşılması için erken yaşlarda astronomiye ait temel kavramların anlaşılması önem taşımaktadır (Sharp, 1999). İkinci olarak çocukların Dünya ve Uzay hakkındaki öğrenme süreçleri, yalnızca bir bilgi edinimi değil, aynı zamanda olağanüstü doğal güzelliklerle tanışma imkânı sunan bir deneyimdir (National Research Council 2001). Üçüncü olarak sorumlu vatandaşlık, sürdürülebilir gelişim ve küreselleşme gibi son yıllarda gittikçe önem kazanan konular çocukların erken yaşlardan itibaren Dünya meseleleri ile tanışmaları gerektiğinin önemini vurgulamaktadır (Ogelman, 2012). Son olarak bireylerin birtakım bilimsel kavramları ve bilimsel düşünme sürecini anlamalarını sağlayan astronomi, erken yaşlardan itibaren bireylerin bilimsel okuryazarlık düzeyini yükseltebilir ve fen eğitiminin ilerlemesine katkıda bulunabilir (Ampartzaki \& Kalogiannakis, 2016). Astronomiye dair kavramların, okul öncesi dönem çocuklarının gelişim düzeyleri göz önünde alındığında soyut kavramlar olduğu ve çocuklar için zorlayıcı olabileceği düşünülse de, bu kavramlar çocuklar için anlaşılamaz değildir. Okul öncesi dönem çocuklarının bu kavramları anlayabilmeleri için öğretimin somutlaştırılması gerekmektedir (Hu, Gordon, Yang \& Ren, 2021). Çocukların yaş ve gelişim özelliklerine uygun yöntemlerin, tekniklerin ve bilimsel bir dilin kullanıldığı öğrenme ortamlarıyla, okul öncesi dönem çocukları astronomiye ilişkin ilk öğrenme deneyimlerini elde edebilirler.

Çocukların astronomi ile ilgili yanlış öğrenmelerinin önüne geçebilmek ve öğrenmeyi somutlaştırmak adına öğrenme ortamları zenginleştirilmelidir. Okul öncesi dönem çocukları yaparak yaşayarak, bilgiyi ilk elden edinerek kalıcı öğrenme gerçekleştirirler. Astronomi ile ilgili kavramlar okul öncesi dönemde çocuklara, gözlem, tahmin, bilimsel iletişim kurma gibi bilimsel süreç becerilerini ve duyularını kullandıkları aktif katılım gösterebilecekleri öğrenme etkinlikleriyle sunulmalıdır. Dolayısıyla astronomi ve astronomik kavramların öğrenimi, görsel ve işitsel materyaller, üç boyutlu modeller, bilgisayar animasyonları ya da yazılımlar ile desteklenmelidir (Demir ve Öner Armağan, 2018). Bu noktada planetaryumlar öne çıkmaktadır.

Planetaryumlar, özellikle astronomiyle ilgili simülasyonlarun özel bir kubbeye yansıtılmasıyla ziyaretçilerin uzayı gözlemlemelerine olanak sağlayan sanal-gerçeklik ortamlarıdır (Bozdoğan, 2020). Evreni keşfetmek için kubbe şeklinde tasarlanmış planetaryum salonlarının yanında farklı planetaryum yazılımları da kullanılabilir. Planetaryum yazılımının kullanılması, zaman, mekan veya konum sınırlaması olmaksızın gerçekçi bir simülasyon ortamı kullanarak gökyüzünü ve uzayı gözlemlemeyi mümkün kılar. Hareketsiz şekiller veya metin açıklamaları yerine farklı astronomik kavramları gerçekçi simülasyonlarla göstermek, öğrenmeyi kolaylaştırır ve kavram yanılgılarını engelleyebilir (Persson \& Eriksson, 2016). Okul öncesi dönemdeki çocukların astronomi kavramlarına ilişkin ilk öğrenmeleri, gelişim özelliklerine uygun bilimsel dil kullanan bir yetişkin rehberliğinde planetaryum yazılımları aracılığıyla da desteklenebilir. Bu çalışmada iki adet açık kaynak kodlu planetaryum yazılımı incelenmiş ve okul öncesi dönemde kullanılabilirliği değerlendirilmiştir.

\section{Materyal ve Yöntem}

Araştırma bir karşılaştırmalı inceleme (comparative review) çalışmasıdır. Öncelikle araştırmada ele alınan açık kaynak kodlu planetaryum yazılımları tanıtılmış, ardından özellikleri, benzerlik ve farklılıkları karşılaştırılarak okul öncesi dönemde kullanılabilirliği tartışılmıştır.

\subsection{Açık kaynak kodlu planetaryum yazılımları}

\subsubsection{Stellarium}

Stellarium, gökyüzünü ve ufku görselleştiren açık kaynak kodlu ücretsiz bir yazılımdır. Gökyüzünü çıplak gözle, dürbünle veya teleskopla görüldüğü gibi gerçekçi bir şekilde üç boyutlu olarak gösterir. Stellarium, bilgisayarların sanal bir planetaryum olarak kullanılmalarına olanak tanıyan bir yazılımdır. Güneş ve Ay'ın, gezegenlerin ve yıldızların konumlarını hesaplar ve gözlemcinin bulunduğu yere ve zamana bağlı olarak gökyüzünün nasıl görüneceğini görselleştirir. Ayrıca takımyıldızlarını, meteor yağmurlarını, kuyruklu yıldızları ve Güneş veya Ay tutulması gibi astronomik olayları simüle edebilir (Steallarium, 2020; Zotti \&Wolf, 2019). Bazı gerçek planetaryum projektör ürünlerinde, grafiklerin yüksek kalitesi nedeniyle Stellarium kullanılmaktadır (Zotti \& Wolf, 2019). Stellarium'da kullanıcı istediği gün ve zaman giderek o ana ait gökyüzünü gözlemleyebilir. Zaman seçeneğini kullanarak zamanı ileriye ya da geriye doğru hızlandırıp yavaşlatarak gökyüzündeki değişimleri gözlemleyebilir.

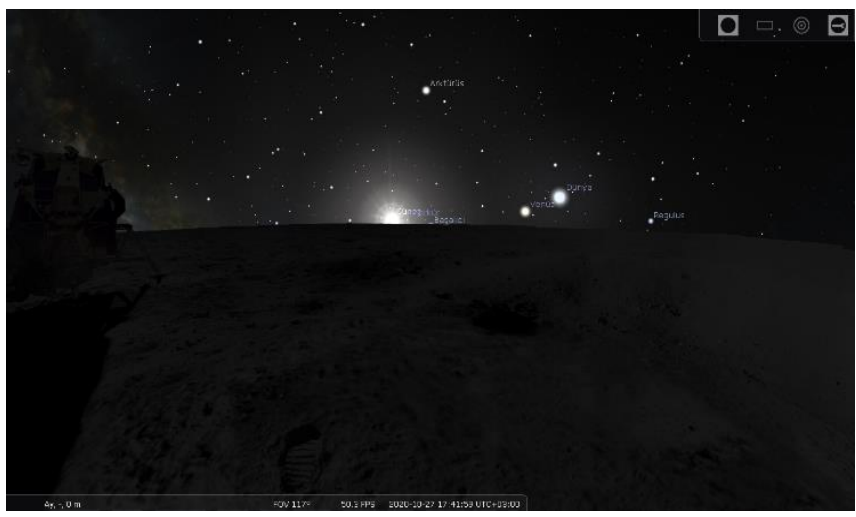

Şekil 1. 27.10.2020 tarihinde 17.41'de Ay'dan Güneş, Venüs, Dünya ve diğer gök cisimlerinin görünümü (Stellarium, 2020).

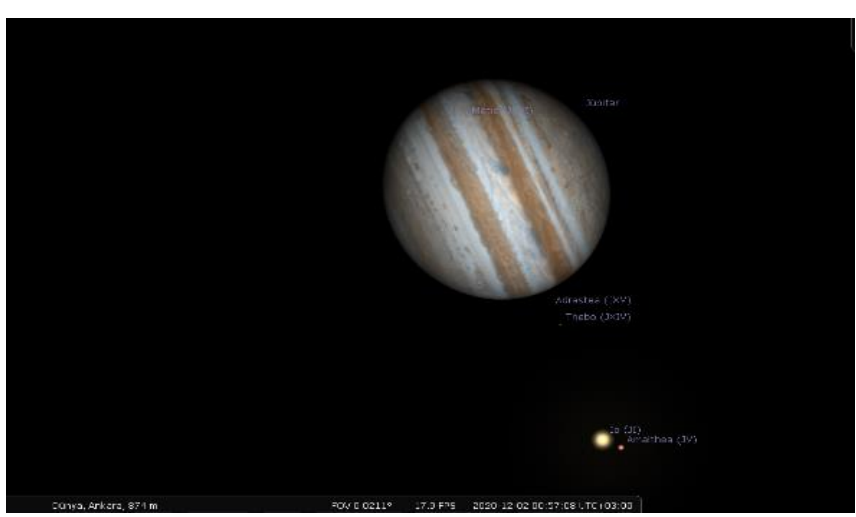

Şekil 2. Jüpiter ve bazı uyduları (Stellarium, 2020).

Programın en büyük avantajı, ücretsiz olması ve Mac, PC ve Linux bilgisayarlar için internetten indirilebilmesidir. Web sitesinde bir kullanım kılavuzu mevcuttur. Web sitesinin ve yazılımın Türkçe dil seçeneği mevcuttur. Programın web sitesinde yer alan minimum sistem gereksinimleri ise Linux/Unix; Windows 7 ve üzeri; Mac OS X 10.12.0 ve üzeri 
işletim sistemi, OpenGL 3.0 ve GLSL 1.3'ü destekleyen 3D grafik kartı, 512 MB RAM, 250 MB disk alanı ve klavyedir (Steallarium, 2020).

\subsubsection{Celestia}

Celestia, ilk sürümü 2001 yılında piyasaya sürülen üç boyutlu bir açık kaynak kodlu uzay simülasyon programıdır. Celestia, kullanıcıya, bir uzay aracının içindeymiş gibi gök cisimlerini gördüğü, uzay aracının konumunu ve yönünü, gözlemlenen nesnenin gerçek hareketine ve hızına göre zamanlamayı kontrol edebildiği bir sanal gerçeklik ortamı sunar. Yazılım, fareyi veya basit klavye kısa yollarını kullanarak boşlukta gezinmeyi mümkün kılar. Güneş sistemindeki Güneş, gezegenler, doğal uydular, uzay sondaları, asteroitler ve kuyruklu yıldızlar gibi gök cisimlerinin gerçek görüntülerini içerir.

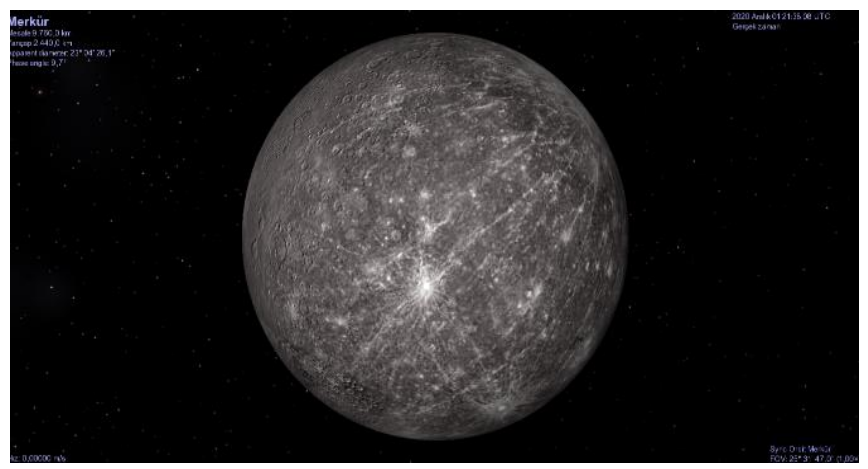

Şekil 3. Merkür (Celestia, 2020).

Windows, Linux, MacOS, iOS ve Android işletim sistemlerinde çalışan Celestia, kullanıcıyı Dünya yüzeyiyle sınırlamayan bir planetaryum yazılımıdır. Kullanıcı, Güneş sistemi boyunca, 100.000 'den fazla yıldızdan herhangi birine ve hatta galaksinin ötesine seyahat edebilir (Celestia, 2020). Programın Türkçe dil desteği mevcuttur. Celestia, en az 64 megabayt video belleğine sahip herhangi bir 3D Open GL hızlandırıcısı ile çalışır. Bununla birlikte, Celestia'nın daha ayrıntılı grafik dosyalarını kullanmak için $128 \mathrm{MB}$ Video RAM kartı ve en büyük eklentiler için 256 MB grafik belleği gerekir.

\section{Bulgular ve Tartıșma}

Okul öncesi dönem çocukları gelişim özellikleri itibari ile, açık kaynak kodlu planetaryum yazılımlarından, öğretmen, ebeveyn ya da herhangi bir yetişkin rehberliğinde yararlanabilir. Her iki yazılım değerlendirildiğinde, Stellarium'un web sitesinde Türkçe dil seçeneğinin olmasi, yazılımı ögretmenler ve ebeveynler için daha kullanışlı hale getirmektedir. Steallarium'un diğer bir özelliği de manzaraların kullanımıdır. Web sitesinde yer alan manzara dosyaları bilgisayara indirildikten sonra Stellarium'a otomatik olarak yüklenebilir. Böylelikle manzara içeren farklı kıtalardan veya farklı gezegenlerdeki noktalardan gökyüzü gözlemlenebilir. Stellarium'un zengin görüntüleme seçenekleri ve alan haritası ekleme özelliği ile eklenecek manzaralar, okul öncesi dönem çocukları için öğrenmeyi daha ilgi çekici ve somut hale getirebilir. Stellarium tüm eğitim seviyelerinde astronominin temellerini öğretmek için kullanılabilecek bir öğretim kaynağıdır (Hughes, 2008).

Planetaryum yazılımları okul öncesi dönemdeki çocuklara, gece-gündüz oluşumu, Güneş'in gün içindeki değişen konumu, Dünya'nın şekli, Ay'ın evreleri, gezegenler ve uyduları, meteor yağmurları gibi pek çok konuya ilişkin ilgi çekici bir öğrenme süreci sunabilir. Kutuplar ve Dünya'nın farklı noktalarından gökyüzünün gece ya da gündüz nasıl görüneceğini ve gök cisimlerinin konumlarını gözlemlemek, çocukların bilime karşı olumlu tutumlarını arttırarak, bilim öğrenmeye olan motivasyonlarını olumlu biçimde etkileyebilir. Çocuklar uzay hakkında merak ettikleri sorulara daha somut cevaplar bulabilir, bilgisayar ve ağ bağlantısının bulunduğu herhangi bir ortamda bir yetişkin rehberliğinde evreni keşfe çıkabilir.

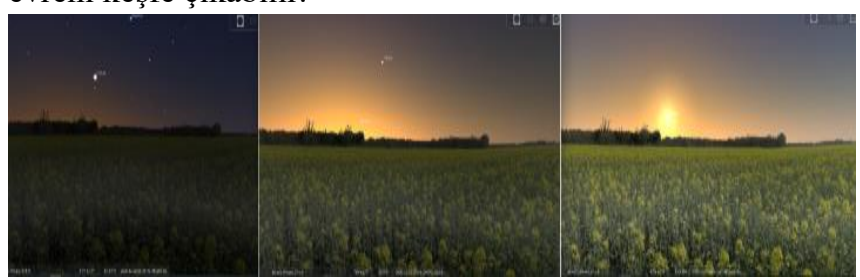

Şekil 4. 02.12.2020 tarihinde Ankara konumundan Güneş'in hareketleri (Stellarium, 2020).

Açık kaynak kodlu planetaryum yazılımları aracılığı ile çocukların yalnızca astronomik kavramlara ilişkin sahip oldukları bilgiler değil, aynı zamanda görsel uzamsal algıları ile gözlem, gruplama, karşılaştırma, ölçme, tahmin, bilimsel iletişim kurma ve sonuç çıkarma gibi bilimsel süreç becerileri de desteklenebilir. İyi planlanan bir öğrenme süreci ile çocuklar gök cisimlerini ve astronomik olayları gözlemleyebilir, gök cisimlerini farklı özelliklerine gruplandırabilir, gök cisimlerinin büyüklüklerini ve uzaklıklarını karşılaştırabilir, Güneş'in belli bir zaman sonra hangi konumda olacağını tahmin edip, gerçek sonuçlarla tahminlerini karşılaştırabilirler. Yetişkinlerle veya akranlarıyla astronomik kavramlar hakkında sohbet edebilir ve gece-gündüz oluşumu, Ay'ın evreleri gibi temel astronomik olaylar hakkında neden-sonuç ilişkileri kurabilirler.

Söz konusu yazılımlardan çocukların faydalanabilmesi için iyi planlanan bir öğrenme sürecinin yanında, çocuğa rehberlik edecek yetişkinin yazılım hakkında bilgi sahibi olması da gerekmektedir. Öğretmenler ve ebeveynler web sitelerinde yer alan kullanım k1lavuzlarından faydalanılarak yazılımlar hakkında bilgi sahibi olabilirler. Yazılımları kullanarak pratik yapabilirler.

\section{Sonuç}

$\mathrm{Bu}$ çalışmada iki farklı açık kaynak kodlu planetaryum yazılımının okul öncesi dönem fen eğitiminde kullanılabilirliği incelenmiştir. Her iki yazılımın benzer ve farklı yönleri mevcuttur. Her iki yazılım da, çocukların gelişim özelliklerine uygun bilimsel bir dil kullanan bir yetişkin rehberliğinde okul öncesi fen eğitimi kapsamında kullanılabilir. Okul öncesi dönem çocuklarının gelişim özellikleri göz önünde bulundurulduğunda, Stellarium bir adım daha öne çıkmaktadır. Yazılımın, çocuklar için anlaşılması güç olan soyut astronomik kavramları daha somut ve çekici olarak sunduğu düşünülmektedir. Stellarium çocukların gece-gündüz kavramı, Ay'ın evreleri, gök cisimlerinin büyüklükleri, Dünya'nın şeklini hakkındaki kavram gelişimlerini ve öğrenmelerini destekleyebilir. Ayrıca 
yazılım, kutup bölgelerinden ve farklı kıtalardan gökyüzünü gözlemleme imkânına sahip olmasıyla çocuklar için ilgi çekici

Kaynaklar

Ampartzaki, M. \& Kalogiannakis, M. (2016). Astronomy in early childhood education: A concept-based approach. Early Childhood Education Journal, 44, 169-179.

Bozdoğan, A. E. (2020). 'Planetaryum' konusunda yayınlanan eğitim araştırmaları makalelerinin Web of Science veri tabanına dayalı bibliyometrik değerlendirilmesi. OPUS Uluslararası Toplum Araştırmaları Dergisi, 16(27), 150-173.

Celestia. (2020). Erişim adresi https://celestia.space/.

Demir, N. ve Öner Armağan, F. (2018). Okul dişı öğrenme ortamlarına yönelik fen bilgisi öğretmenlerinin görüşleri. Journal of Social and Humanities Sciences Research (JSHSR), 5(30), 4241-4248.

Hu, J., Gordon, C., Yang, N., \& Ren, Y. (2021). 'Once Upon A Star': A science education program based on personification storytelling in promoting preschool children's understanding of astronomy concepts. Early Education and Development, $32(1), 7-25$.

Hughes, S. W. (2008). Stellarium-a valuable resource for teaching astronomy in the classroom and beyond. Science Education News (SEN), 57(2), 83-86.

İzgi Onbaşılı, Ü. ve Siper Kabadayı, G. (2019). Okul öncesi dönemde çocukların astronomi konusunda temel kavramlarla ilgili bilgilerinin incelenmesi. Turkish Journal of Primary Education, 4(2), 85-97.

Kallery, M. (2011). Astronomical concepts and events awareness for young children. International Journal of Science Education, 33(3), 341-369.

Lind, K. K. (1999). Science in early childhood: Developing and acquiring fundamental concepts and skills, dialogue on early childhood science, mathematics, and technology education. Washington, DC: AAAS.

National Research Council (2001). Astronomy and astrophysics in the new millennium. Washington, DC: The National Academies Press.

Ogelman, H. G. (2012). Teaching preschool children about nature: A project to provide soil education for children in Turkey. Early Childhood Education Journal, 4O(1), 77-185.

Persson, J. R. and Eriksson, U. (2016). Planetarium software in the classroom. Physics Education, 51(2), 1-9.

Sharp, J. G. (1999). Young children's ideas about the Earth in space. International Journal of Early Years Education, 7(2), 159-172.

Stellarium. (2020). Erişim adresi http://stellarium.org/.

Timur, S., Yalçınkaya-Önder, E., Timur, B. ve Özeş, B. (2020). Astronomy education for preschool children: Exploring the sky. International Electronic Journal of Elementary Education, 12(4), 383-389.

Zotti, G. \& Wolf, A. (2019). Stellarium 0.19. O User Guide, 2019. Available at https://stellarium.org. bir öğrenme aracı haline gelebilir. 